\title{
Lip Print as a Method for Forensic Identification on Malaysian with Chinese Ethnicity
}

\author{
Yendriwati ${ }^{1}$, Joey Wong Joe ${ }^{2}$, Atika Resti Fitri ${ }^{3}$ \\ ${ }^{1}$ Faculty of Dentistry, Department of Oral Biology, Universitas Sumatera Utara, Indonesia. \\ ${ }^{2}$ Faculty of Dentistry, Department of Oral Biology, Universitas Sumatera Utara, Indonesia. \\ ${ }^{3}$ Faculty of Dentistry, Department of Oral Biology, Universitas Sumatera Utara, Indonesia.
}

\section{ABSTRACT}

\section{BACKGROUND}

Forensic dentistry is a branch of forensic medicine that has now become a standalone science. Lip print is used to identify forensic and non-forensic cases. The aim of this research is to find the pattern of lip print based on Suzuki and Tsuchihashi classification according to quadrant, to investigate the difference of dominant lip print pattern in general and also according to the different gender (male and female) among Malaysians with Chinese ethnicity at University of Northern Sumatra.

\section{METHODS}

The subjects were male and female Malaysian Chinese students at University of Northern Sumatra. The study sample consisted of 30 students, 15 each of males and females. Subject's lips were applied with lipstick and cellophane tape to lift lip print for observation. Data was analysed by using Chi-square test.

\section{RESULTS}

Our study demonstrated that Malaysian Chinese students generally have type II as a dominant lip print pattern. As shown by Chi-square test, there was a significant difference between male and female lip print patterns. Type II lip print patterns was the highest number found in males, whereas type IV was in females. In general, type II was most common.

\section{CONCLUSIONS}

The dominant lip print pattern of Malaysian Chinese is Type II. The difference of lip print pattern between males and females lies on type IV.

\section{KEY WORDS}

Lip Prints, Forensic Identification, Malaysian Chinese
Corresponding Author: Yendriwati, Jalan Alumni No. 2, Kampus USU Medan, North Sumatera, Indonesia. E-mail:drg.yendriwati@gmail.com

DOI: $10.14260 / \mathrm{jemds} / 2019 / 615$

Financial or Other Competing Interests: None.

How to Cite This Article: Yendriwati, Joe JW, Fitri AR. Lip print as a method for forensic identification on Malaysian with Chinese ethnicity. J. Evolution Med. Dent. Sci. 2019;8(37): 2831-2835, DOI:
Submission 08-10-2018,

Peer Review 28-08-2019,

Acceptance 05-09-2019,

Published 16-09-2019. 


\section{BACKGROUND}

Forensic dentistry is a branch of forensic medicine which is now an independent field of study. Forensic dentistry or odontology is a branch of dentistry which is focus on the evaluation of results of the discovery related to the oral cavity for justice purposes. ${ }^{1}$ The history has existed since prehistoric times, but only began to get noticed in the late 19 th century. Since then many cases of forensic odontology have been reported in the literature so that the name of forensic odontology is well known not only among physicians but also among law enforcement and forensic experts. ${ }^{2}$ Identification is the determination and assurance of the identity of a living person or a dead person based on the characteristics of that person. The scope of identification in forensic dentistry is broad, covering not only forensic but also non-forensic problems. Identities that support the identification of a victim may be biological and non-biological. Non-biological identities may include identity cards, driver's licenses, clothing and so on. Biological identity is obtained from bones, teeth, blood, fingerprints, hair, DNA profile and lip prints. Lip print as a means of identification can be used to identify forensic and non-forensic cases. In forensic cases lipprint is used to solve murder cases, while it is required to identify age, gender, and race in non-forensic cases. ${ }^{3}$ According to Hinton et al., race is a unity of group of people due to the similar physical and spiritual attributes. They inherit, which make them distinguishable from one to another. Haldane stated that race is a unity of physical character and geographical origin in a particular area. ${ }^{4}$ Chinese belong to the Asiatic-Mongoloid sub-race with physical features such as straight black hair, slanted eyes and yellowish white complexion. ${ }^{5}$

Lips print is one of the potential methods for the identification of individuals first mentioned by R. Fischer in 1902. In 1930, Diou de Lille conducted several studies regarding the use of lipstick in the case of criminologists. The famous French criminologist Edmond Locard found that lipstick can be used as a method of support in the identification process in 1932. However, before 1950 anthropologists rarely called the embodiment of plots and functions practically. ${ }^{6}$ The idea of using lipstick as a way of identification was first introduced by LeMoyne Snyder to help forensic scientists. In addition Martin Santos, in 1960, suggested that the grooves on the surface of the lips is classified into different groups. ${ }^{7}$ Renaud in 1972 observed 4,000 lipsticks to confirm the uniqueness of lipstick, no study are the reported of having the same lip print. ${ }^{8}$ Lip prints grooves on the vermilion or red part of lips. These grooves may include several patterns including vertical, branched, intersecting, and other lines. ${ }^{7}$ Similarly, fingerprints are unique to each individual, and have high persistence. The grooves begin to persist from the 6th week of intra-uterus until the individual pasts away. ${ }^{9}$ Therefore, lipstick is potentially used as an individual identification tool. There are several methods to obtain lip prints such as lipstick method, dental impression materials, fingerprint dye powder and photography. Among those lipstick is the simple method and can be performed directly. To obtain optimal results, lip print should be done correctly. ${ }^{10}$

Lip prints are often recorded in crime scene on spoon surface, wind instrument, glasses on fruits. It may be in different mouth positions, such as resting, opened, smiling or kissing. Lip prints may show differently due to contraction of the muscles. This results in only vertical (Perpendicular) but not horizontal (Transverse), grooves are observed.11 In a rested state, the grooves or crevices of the lips appear more obviously, whereas the grooves or clefts are less clear and hardly to interpret. ${ }^{8}$ However, several studies have been reported to identify and classify lip print patterns, but has not been determined of which classification of lip prints as the international reference. Suzuki and Tsuchihahsi, Renaud, Kasprzak, José Maria Dominiguez, Martin Santos, and AfcharBayat classification have been commonly used in lip print classification.6,7,8,9 Tsuchihashi suggests the four-quadrant method. It was found that lip prints on a single lip did not consist of only a single pattern, but a combination of several patterns. The lip is divided into 4 quadrants starting from the top right and ending with the lower right. ${ }^{12}$ Jatti and Rastogi previously identified lip prints pattern using Suzuki and Tsuchihashi classification in South Indian Population and found that all subjects have distinct patterns. However, a similar study related to the ethnic of Malaysian Chinese has been unpublished yet. Therefore, this study aims to investigate dominant lip print pattern between male and female students of Malaysian Chinese at University of North Sumatera using Suzuki and Tsuchihashi classification.

\section{METHODS}

This study was a cross-sectional design by collecting the data of Chinese students' lip prints at University of Northern Sumatra, Medan. This research was approved by Health Research Ethical Committee of Faculty of Medicine, University of North Sumatera and then conducted in the Oral Biology Laboratory, Faculty of Dentistry, University of Northern Sumatra, Medan. The population of this research was Malaysian Chinese students in University of Northern Sumatra, Medan. Samples were obtained by purposive sampling. The subjects were collected based on certain characteristics, properties, areas and objectives inclusion and exclusion criteria were also included

Thirty people consisting of 15 male and 15 female were selected. The subjects with inclusion criteria, 2 generations of Malaysian Chinese, and students in University of Northern Sumatra, individuals without growth abnormalities, aged 20 26 years old, and relation of jaw occlusion classified as Class I Angle. Individuals with hypersensitivity towards lipstick, pathological conditions on the lips during the study (either active or passive lesions), history of surgery on the lips, and individuals with deformities on the lips post-accident belonged to exclusion criteria Subject were given questionnaires form to fill in after signing inform consent. White paper, scotch tape, magnifying glass, black and blue markers, $70 \%$ alcohol, lipstick, lip liner, tissue, mask, and gloves were used to perform the method. Suzuki and Tsuchihashi Classification was related in the lip prints into 6 types of patterns or grooves: Type I (full vertical), Type I (partial vertical), Type II (branching), Type III (intersection), Type IV (reticular) and Type V (other types of groove) (Figure 1). 


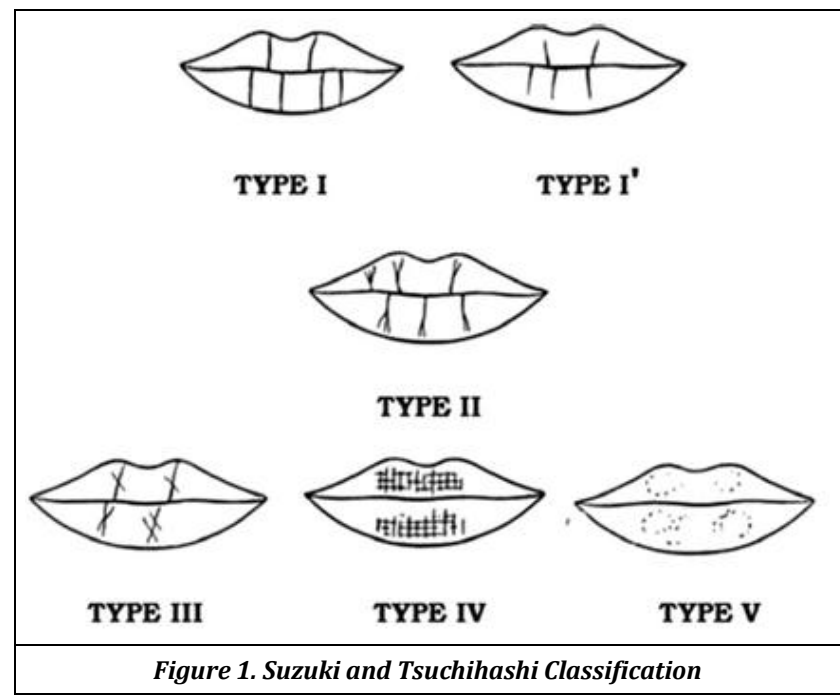

The lip prints taken in this study was observed and calculated according to the method performed by Tsuchihashi (1974), the lip prints were divided into 4 quadrants and counted one by one. This method was selected chosen because it had non-subjective results. Dominant lip prints pattern is the most predominantly imprinted in all quadrants. Dominant lip prints pattern according to quadrant refers to the mostly found lip prints in each quadrant. The lips of the subjects were firstly sanitized with $70 \%$ alcohol. In a closed position vermilion border of the lip was marked with lip liner and lipstick was then on. Scotch tape was used to obtain lip prints after marking the midpoint of both lips with black marker pen in the philtrum for the upper lip and the midpoint of the lower lip. The tape was subsequently removed and placed on a white paper and labelled with numbers. Minimum pressure was subsequently during the process of obtaining lip print. The lip print was then divided into 4 quadrants and observed using a magnifying glass. The lip pattern of each quadrant was recorded on the contents sheet, and the dominant lip print pattern was determined on the observer sheet with the highest number of lip patterns per quadrant. (Figure 2)

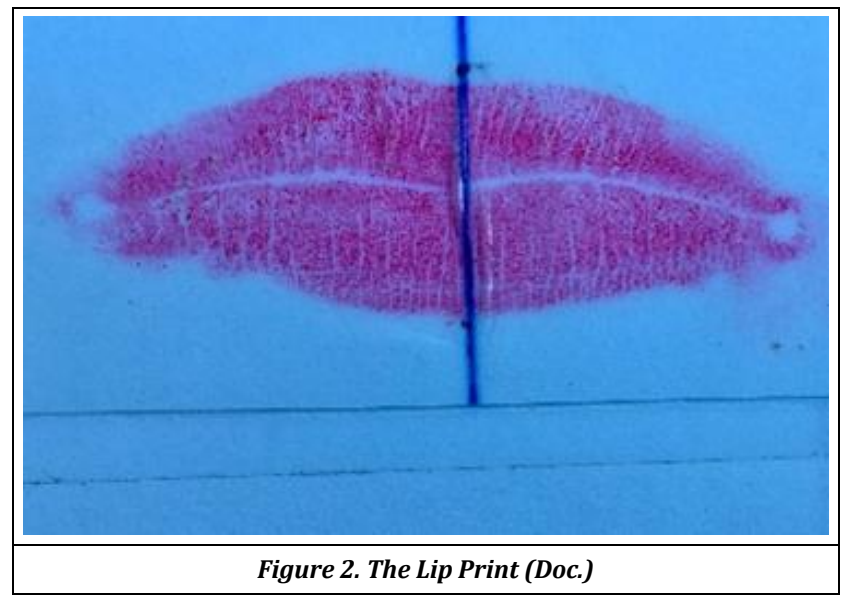

Data were analysed using SPSS version 23 program. Chisquare test was used to determine the difference. T-test was used to show if there is a significant difference between the types of dominant lip print patterns on male and female subjects.

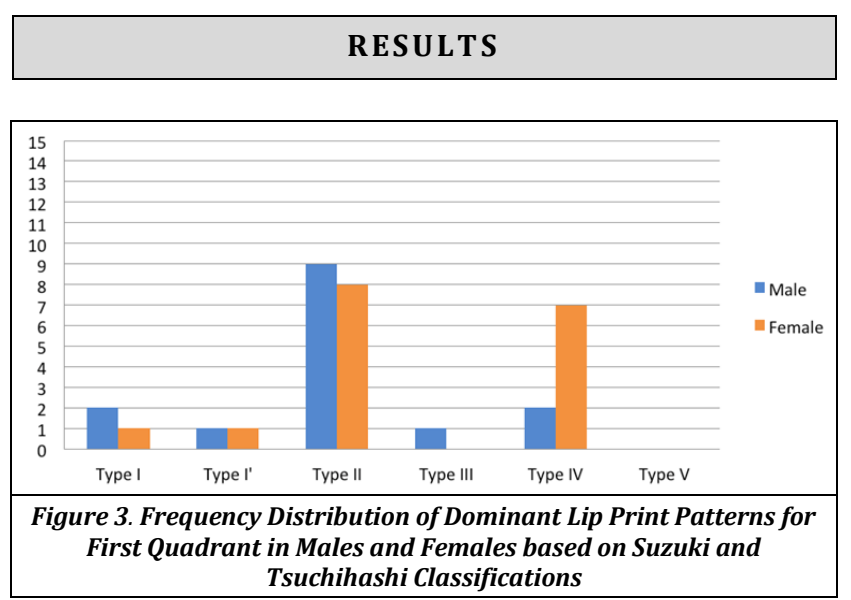

The $1^{\text {st }}$ quadrant, dominant lip print pattern of males was the type II ( 9 persons, $30 \%$ ), and the least was type I and type III, 1 person each $(3.3 \%)$. Type $\mathrm{V}$ lip print pattern was not found dominantly. The dominant lip print pattern found in females was type II (8 persons, $26.7 \%$ ), followed by type IV ( 7 persons, $23.3 \%$ ).

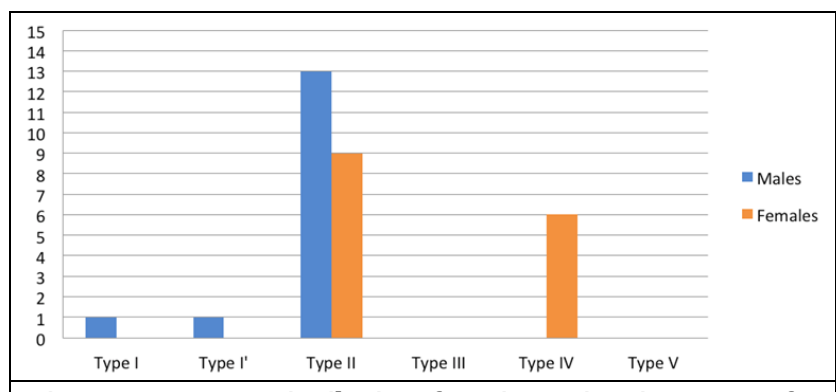

Figure 4. Frequency Distribution of Dominant Lip Print Patterns for Second Quadrant in Males and Females Based on Suzuki and Tsuchihashi Classifications

The 2nd quadrant, dominant lip print patterns of males was type II (13 persons, 43.3\%) and the less dominant were type I and type I', each 1 person (3.3\%). Other lip print patterns were not found dominantly. The dominant lip print pattern of females was also type II ( 9 persons, 30\%), followed by type IV ( 6 persons, $20 \%$ ). Other lip print patterns were not found dominantly.

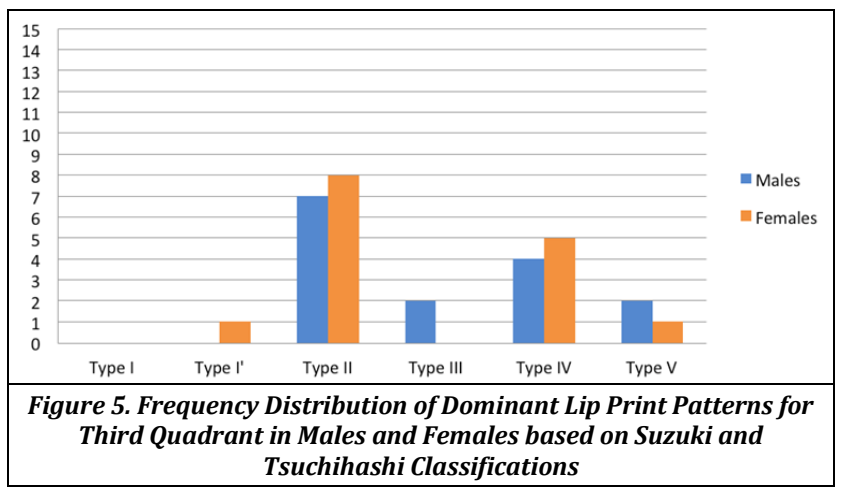

The $3^{\text {rd }}$ quadrant, dominant lip print pattern for males was type II (7 persons, 23.3\%), followed by type IV (4 persons, $13,3 \%$ ), and the least was type III and type V, 2 persons each (6.7\%). Type I and type I' was not found 
dominantly. The dominant lip print pattern for females was type II ( 8 persons, $26.7 \%$ ), followed by type IV (5 persons, $16.7 \%)$, and the least was type I' and type V, 1 person each (3.3\%). Type I and type III was not found dominantly.

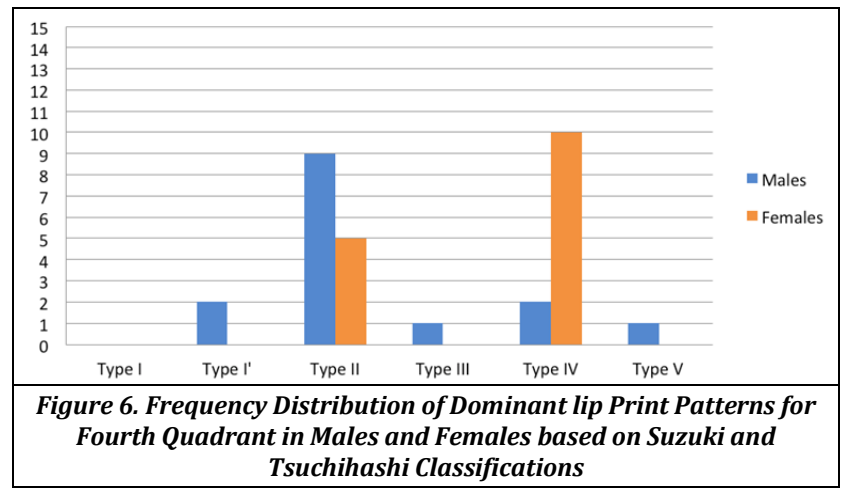

The $4^{\text {th }}$ quadrant, dominant lip print pattern for males was type II ( 9 persons, 30\%), followed by type I' and type IV, 2 persons each (6.7\%), and the least was type III and type $\mathrm{V}, 1$ person each $(3.3 \%)$. Type I was not found dominantly. The dominant lip print pattern in females was type IV (10 persons, $33.3 \%$ ), followed by type II (5 persons, $16.7 \%$ ). Other lip print patterns were not found dominantly.

\begin{tabular}{|c|c|c|c|c|c|c|c|}
\hline \multirow{3}{*}{$\begin{array}{l}\text { Lip Print } \\
\text { Patterns }\end{array}$} & \multicolumn{4}{|c|}{ Sex } & \multirow{2}{*}{\multicolumn{2}{|c|}{ Total }} & \multirow{3}{*}{ Sig. } \\
\hline & \multicolumn{2}{|c|}{ Male } & \multicolumn{2}{|c|}{ Female } & & & \\
\hline & $\mathrm{n}$ & $(\%)$ & $\mathrm{n}$ & (\%) & $\mathrm{n}$ & (\%) & \\
\hline Type I & 1 & 3.3 & 0 & 0.0 & 1 & 3.3 & \multirow{7}{*}{0.048} \\
\hline Type I' & 1 & 3.3 & 0 & 0.0 & 1 & 3.3 & \\
\hline Type II & 11 & 36.7 & 6 & 20.0 & 17 & 56.7 & \\
\hline Type III & 0 & 0.0 & 0 & 0.0 & 0 & 0.0 & \\
\hline Type IV & 2 & 6.7 & 9 & 30.0 & 11 & 36.7 & \\
\hline Type V & 0 & 0.0 & 0 & 0.0 & 0 & 0.0 & \\
\hline Total & 15 & 50.0 & 15 & 50.0 & 30 & 100.0 & \\
\hline
\end{tabular}

Table 1. Total and Percentage Distribution of Dominant Lip Print Patterns of Male and Female Based on Suzuki and Tsuchihashi Classification

significance level $\mathrm{p}<0,05$

Chi-square test results showed that the significance value was $0.048<0.05$, which means $\mathrm{H}_{0}$ hypothesis was rejected. The results of this test indicate that there is a significant difference in the dominant lip print patterns between males and females based on Suzuki and Tsuchihashi classification on Malaysian Chinese. Type II lip print patterns was the highest number found in males, whereas type IV was in females. In total number (male and female), the percentage of type IV was less than type II. However, type II was the most common showed in table 1.

\section{DISCUSSION}

The development of human facial embryology occurs at week 4 after fertilization, whereas lips embryology began a at week 5. Two protrusions of maxillary prominence continue its growth towards the middle and suppress the medial nasal prominence towards the midline. In this process, the gap between the medial nasal prominence and maxillary prominence disappear, and the two protrusions coalesce. The unification of these two projections form the philosophy and the upper lip. The lower lip and jaw are derived from mandibular prominence that fused along the midline. ${ }^{13}$ The lips are two muscle folds that make up the gate of oral cavity, consisting of the upper and lower lip. The outer lips are covered by skin tissue, while the inside is covered by the oral mucosa. The lips are part of the oral cavity, starting from the skin-vermilion border and covering the entire vermilion. The lips consist of three parts, namely skin, vermilion and mucosa. The upper lip is composed by three units, which are 2 laterals and 1 medial. The cuspid bow is the downward projection of the philtrum unit which gives the shape of the lip, the upper and lower lip boundaries circularly on the cutaneous border and the vermilion is known as the white roll. Bottom lip has 1 unit of labiomental groove part that separates the lips with the chin. ${ }^{13}$

The outer surface of the lips is covered by skin, hair follicles, sebaceous and sweat glands. The edge of the vermilion is a transition between the skin and the mucous membrane, the lips turn into a hairless thin skin, with a transparent epidermis. ${ }^{14}$ The epidermis at the edge of the vermilion is transparent, and the dermis consists of many blood vessel plexuses giving the red colour on the lips. ${ }^{11}$ Lip prints are similar to fingerprints with unique characteristics and different for each individual, lip print pattern is distinct from one to another. The characteristics of lips and fingerprint patterns can be used as a comparative identification, i.e. comparing antemortem with post-mortem data of the victim to identify their identity. ${ }^{15}$ Differences between lip prints and fingerprints pattern are their position, lip print patterns are on the surface of the epidermis while fingerprints are between the epidermis and dermis layer of skin.

The results of $1^{\text {st }}$ quadrant (Figure 2) show that the dominant lip print pattern highest of male is type II, with 9 persons (30\%). The results of this research on female also shows that the dominant lip print pattern is type II with a total of 8 persons $(26.7 \%)$. The result of this research is consistent with the result of Juniastuti et al. Study Otherwise from Randhawa et al. found that the dominant lip print pattern of both sexes is type I. This may be due to the different race collected in the study of Randhawa et al. Punjab ethnic which was grouped in Caucasian race, whereas in Juniastuti et al was Javanese and our study was Chinese, both were grouped in Mongoloid race.11,16 The results of the $2^{\text {nd }}$ quadrant (Figure 3) show the dominant lip print patterns highest of male is type II with 13 person $(43,3 \%)$ and female 9 person (30\%). The results of this research differ from Juniastuti et al. which concluded that dominant lip print patterns of both sexes were type IV. This may be due to subracial differences in which the research subjects Juniastuti et al. was a Javanese ethnic group belonging to the PaleoMongoloid sub-race while subjects in this research was Malaysian Chinese belonging to the Neo-Mongoloid subrace. ${ }^{11}$ The results of the $3^{\text {rd }}$ quadrant (Figure 4) show that the dominant lip print patterns highest on both sexes was type II which is male 7 person $(23,3 \%)$ and female 8 person $(26,7 \%)$. Similar to Juniastuti et al. research but not in a study by Kapoor et al, which found that the dominant lip print patterns of both sexes were type I. This may be due to racial differences in which the study subjects. Kapoor et al. was of Marathi ethnic which is a Caucasian race while Juniastuti et al. used Javanese ethnic and this study was Chinese ethnic, both are of Mongoloid race.11,17 The result of the research in $4^{\text {th }}$ quadrant (Figure 5) shows that the dominant lip print 
pattern highest of male is type II ( 9 persons $30 \%$ ) whereas in female is type IV (10 persons, 33,3\%).

The highest number of dominant lip print patterns for four quadrant of male was type II (11 persons, 36.7\%) and female was type IV ( 9 persons, $30 \%$ ) followed type II (6 persons, $20 \%$ (Table 1). The results of this study is differences to that of Juniastuti et al. which concludes that the dominant lip pattern in both sexes is type II.11 This research males have dominant lip print pattern was type II while females type IV. The results of this research indicate that Malaysian Chinese generally have a dominant lip print pattern of type II and type IV. Chi-square test showed a significant value 0.048. In line with Rao et al. (Malacca, 2014) with a significant value of $\mathrm{P}<0.001$, these differences in dominant lip print pattern showed that there was a correlation between lip print patterns and sex, which might be helpful in forensic identification. ${ }^{18}$ Research and information on lip print which can be used as an evidence to identify an individual's identity, and also in criminal investigation in forensic dentistry. Lip print patterns is useful in cases of murder, rape and robbery as long as the lips are intact and undamaged, and still within 24 hours of the post death. ${ }^{19}$

\section{CONCLUSIONS}

For Malaysian Chinese, the dominant lip print pattern for male was type II, and female type IV and type II. There is a difference between dominant lip print patterns of both sexes based on Suzuki and Tsuchihashi classification with a significant value of 0.048 . Based on type the dominant lip print patterns: type I, type I' and type II does not have a significant value between both sexes, whereas type IV has a significant value of 0.007 . further studies with larger sample are required to compare Malaysian Chinese lip print pattern with other ethnic's lip print pattern. It is advised to all dental practitioners to have lip prints of all patients as an antemortem data.

\section{REFERENCES}

[1] Reddy LVK. Lip prints: an overview in forensic dentistry. J Adv Dent Research 2011;2(1):17-20.

[2] Bajpai M, Mishra N, Yadav P, et al. Efficacy of lip prints in determination of sex and inter observer variability. European J Experimental Biology 2011;1(4):81-6.

[3] Septadina IS. Identifikasi individu dan jenis kelamin berdasarkan pola sidik bibir. J Kedokteran Kesehatan 2015;2(2):231-6.
[4] Hinton CF, Grant AM, Grosse SD. Ethical implications and practical considerations of ethnically targeted screening for genetic disorders: the case of haemoglobin screening. Ethnicity \& Health 2011;16(4-5):377-88.

[5] Tanasyah Y. Penggolongan ras penduduk Asia. https://tanasyah.wordpress.com/2011/11/24/penggol ongan-ras-penduduk-asia/ (13 Juni 2016).

[6] Kasprzak J. Cheiloscopy. In: Siegel JA, Pekka SJ, Geodfrey CK, eds. Encyclopedia of Forensic Sciences. $1^{\text {st }}$ edn. Warsaw: Academic Press 2000: p. 358-61.

[7] Tsuchihashi Y. Studies on personal identification by means of lip prints. Forensic Sci 1974;3(3):233-48.

[8] Atreja G. Cheiloscopy and palatoscopy. In: Jain N, edr. Forensic odontology. Karnataka: Jaypee Brothers Medical Publishers 2009.

[9] Caldas IM, Magalhães T, Afonso A. Establishing identity using cheiloscopy and palatoscopy. Forensic Sci Int 2007;165(1):1-9.

[10] Atmaji M, Yuni M, Atmadja DS. Metode pengambilan sidik bibir untuk kepentingan identifikasi individu. J PDGI 2013;62(3):64-70.

[11] Juniastuti M, Suisna I. Perbandingan antara pola sidik bibir posisi normal dengan pada posisi bibir terbuka, tersenyum dan mengecup. Indonesian J Dent 2005;12(2):100-2.

[12] Susilo KP. Identifikasi jender berdasarkan pola sidik bibir dan sidik jari. Tesis, Jakarta: FKG UI, 2013: p. 8-13.

[13] Sadler TW. Langman's medical embryology. $12^{\text {th }}$ edn. Baltimore: Lippincott William \& Wilkins 2012: p. 276-7.

[14] Venkatesh R, David MP. Cheiloscopy: an aid for personal identification. J Forensic Dent Sci 2011;3(2):67-70.

[15] Saraswathi TR, Gauri M, Ranganathan K. Study of lip prints. J Forensic Dent Sci 2009;1(1):28-31.

[16] Randhawa K, Narang RS, Arora PC. Study of the effect of age changes on lip print pattern and its reliability in sex determination. J Forensic Odontostomatol 2011;29(2):45-51.

[17] Kapoor N, Badiye A. A study of distribution, sex differences and stability of lip print patterns in an Indian population. Saudi J Bio Sci 2017;24(6):1149-54.

[18] Rao BK, Srinivasan SR, Natarajan D. Evaluation and comparison of lip print patterns among Indians, Chinese and Malay. GUIDENT 2014: p. 16-8.

[19] Dineshshankar J, Ganapathi N, Yoithaprabhunath TR, et al. Lip prints: role in forensic odontology. J Pharm Bioallied Sci 2013;5(Suppl 1): S95-7. 